\title{
Effects of Ethylcellulose and 2-Octyldodecanol Additives on Skin Permeation and Irritation with Ethylene-Vinyl Acetate Copolymer Matrix Patches Containing Formoterol Fumarate
}

\author{
Ikuhiro Kakubari, ${ }^{*}, a$ Hiroyuki Sasaki, ${ }^{a}$ Toshiyuki TakaYasu, ${ }^{a}$ Hitoshi Yamauchi, ${ }^{a}$ \\ Satoshi TAKAYAMA, ${ }^{a}$ and Kozo TAKAYAMA ${ }^{b}$ \\ ${ }^{a}$ Research Department, Saitama Daiichi Pharmaceutical Co., Ltd.; 8-1 Minamisakae-cho, Kasukabe, Saitama 344-0057, \\ Japan: and ${ }^{b}$ Department of Pharmaceutics, Hoshi University; 2-4-41 Ebara, Shinagawa-ku, Tokyo 142-8501, Japan. \\ Received March 29, 2006; accepted May 27, 2006; published online June 2, 2006
}

\begin{abstract}
Skin permeation of formoterol fumarate (FF) and irritation with ethylene-vinyl acetate (EVA) copolymer matrix patches was investigated using rat and human skin in vitro and different species of experimental animal, respectively. Skin permeation of FF increased remarkably without addition of ethylcellulose (EC) and was remarkably enhanced by incorporation of 2-octyldodecanol (OD) instead of hydrogenated rosin glycerol ester (Ester Gum H). Effects on skin permeation of FF with EVA matrix patches were similar in rat and human skin, but rat skin was 1000 times more permeable than human skin after $24 \mathrm{~h}$. The primary irritation indices for matrix patches without EC and with EC (OD-0), EC and $0.5 \mathrm{mg}$ OD per square centimeter (OD-0.5), and EC and $1.0 \mathrm{mg}$ OD per square centimeter (OD-1) were 1.46, 1.13,1.29 and 1.38. The results suggested that the irritation induced by these patches was rather mild, but significantly greater than the 0.21 observed with the control. No significant effects were noted for either EC or OD alone. Skin irritation intensity with EVA matrix patches was observed to be in the order of rabbits, guinea pigs, rats and miniature swine.
\end{abstract}

Key words skin; permeation; irritation; formoterol

Formoterol is a catecholamine analogue possessing highly potent, long-lasting $\beta_{2}$-adreoceptor agonist effects. ${ }^{1,2}$ Clinical studies have revealed that it induces bronchodilation for at least $12 \mathrm{~h}$ after a single oral administration. ${ }^{3,4)}$ However, in order to maintain effective plasma concentrations and suppress asthmatic fits, there is considerable interest in development of transdermal drug delivery systems.

Transdermal drug delivery is well recognized as an alternative to oral delivery and has many advantages, including the avoidance of metabolism in the gastrointestinal tract and the liver, long-term maintenance of therapeutic plasma levels of drugs and ready discontinuation of drug input if side effects arise.

However, without the use of skin permeation enhancers, systemic delivery of most drugs through the skin is limited due to the barrier function of the stratum corneum. Such agents increase drug transport through the skin by elevating partition and diffusion coefficients. Ideally enhancers should increase drug transport by reversibly altering the skin barrier function without sensitization or irritation. We have already reported effects of $l$-menthol and $N$-methyl-2-pyrrolidone (NMP) on skin permeability and stability of formoterol fumarate (FF) in matrix patches. ${ }^{5)}$ Furthermore, efficacy under simulated conditions relevant to asthma in experimental animals was demonstrated. However, no significant effects were observed with 2-octyldodecanol (OD) on rat skin permeability of FF in solution. ${ }^{6}$

In the present study, we evaluated the skin permeability of FF and irritation of EVA matrix patches containing ethylcellulose (EC) and OD using different species of experimental animal.

\section{MATERIALS AND METHODS}

Materials FF and bromo-formoterol were obtained from
Yamanouchi Pharmaceutical Co., Ltd. (Tokyo, Japan) and ethylene-vinyl acetate copolymer (MW: 396000) of 45\% (w/w) vinyl acetate content (EVA), hydrogenated rosin glycerol ester (Ester Gum H), EC, OD, l-menthol, and NMP were purchased from Bayer AG (Tokyo, Japan), Arakawa Chemical Co., Ltd. (Osaka, Japan), Dow Chemical Co. (Tokyo, Japan), Kokyu Alcohol Kogyo Co., Ltd. (Chiba, Japan), Takasago International Co. (Tokyo, Japan) and ISP Japan Ltd. (Tokyo, Japan), respectively. All other chemicals and solvents were of reagent grade quality, obtained commercially and used without further purification.

Preparation of EVA Matrix Patches EVA matrix patches were prepared by a casting method. ${ }^{7,8)}$ An adhesive solution was made by adding EVA, Ester Gum H, EC and OD to toluene as a coating solvent and mixing with a magnetic stirrer at room temperature. FF was dissolved at NMP followed by addition of $l$-menthol. The drug solution was then mixed with the adhesive solution and the mixture applied to a baking sheet of polyethylene terephthalate film. After drying at $50^{\circ} \mathrm{C}$ for $10 \mathrm{~min}$, a release liner was placed on the dry adhesive. The compositions of the matrix patches on prescription are shown Table 1. The adhesive layer of the EVA matrix patch without EC was adjusted to $68 \mu \mathrm{m}$ thickness and with EC were $80 \mu \mathrm{m}$. EVA matrix patches were stamp excised at $7.07 \mathrm{~cm}^{2}$ and their weights were measured. All EVA matrix patches were transparent.

In Vitro Rat Skin Permeation Study Hair on the abdominal skin of male Wistar strain rats (Nihon SLC, body weight $170-200 \mathrm{~g}$ ) was shaved, and full-thickness skin was excised and preserved at $-40^{\circ} \mathrm{C}$ until mounted in modified Frantz diffusion cells (available diffusion area, $0.95 \mathrm{~cm}^{2}$; volume of receiver cell, $4.0 \mathrm{ml}$ ) used for evaluation. EVA matrix patches were stamp excised at $0.95 \mathrm{~cm}^{2}$ and applied to the skin on the donor side. The receiver side was filled with saline, stirred with a magnetic stirrer. At appropriate inter- 
Table 1. Compositions of EVA Matrix Patches per Square Centimeter

\begin{tabular}{lcccc}
\hline \hline \multirow{2}{*}{ Ingredient } & \multicolumn{4}{c}{ Quantity (mg) } \\
\cline { 2 - 5 } & Without EC & OD-0 & OD-0.5 & OD-1 \\
\cline { 2 - 5 } FF & 0.08 & 0.08 & 0.08 & 0.08 \\
l-Menthol & 1.50 & 1.50 & 1.50 & 1.50 \\
NMP & 0.52 & 0.52 & 0.52 & 0.52 \\
EVA & 2.83 & 2.83 & 2.83 & 2.83 \\
Ester Gum H & 1.85 & 1.85 & 1.35 & 0.85 \\
EC & - & 1.25 & 1.25 & 1.25 \\
OD & - & - & 0.50 & 1.00 \\
\hline
\end{tabular}

vals, $0.3 \mathrm{ml}$ samples were taken from the receiver solution and replaced by the same volume of fresh saline to maintain a constant volume.

Collected samples were made alkaline by the addition of $1.0 \mathrm{ml}$ of $0.5 \mathrm{M}$ phosphate buffer $(\mathrm{pH} \mathrm{9.0)}$ and extracted with $3.0 \mathrm{ml}$ of ethyl acetate. After vigorous shaking for $10 \mathrm{~min}$, the organic layer was separated by centrifugation at 3000 rpm for $10 \mathrm{~min}$, and $2.5 \mathrm{ml}$ of the organic layer was transferred to a centrifuge tube, and evaporated in a nitrogen stream at $40^{\circ} \mathrm{C}$. The residue was redissolved in $0.3 \mathrm{ml}$ of $0.1 \mathrm{M}$ of phosphate buffer ( $\mathrm{pH} 3.5)$, and the concentration of formoterol was determined by HPLC using an electrochemical detector . This assay achieved a sensitivity limit of detection of $1 \mathrm{ng} / \mathrm{ml}$.

Determination of FF by HPLC with Electrochemical Detection The HPLC system consisted of a Model AS-950 autosampler, a Model PU-980 pump (JASCO Co., Tokyo, Japan) and an ECD-100 glassy carbon electrochemical detector (Eicom Co., Kyoto, Japan). The detector potential was set at $+650 \mathrm{mV}$ versus an $\mathrm{Ag} / \mathrm{AgCl}$ reference electrode. The analytical column was a Nucleosil 100-5C18 (4.0×150 mm I.D.) (GL Sciences Inc., Tokyo, Japan) and the mobile phase consisted of $0.1 \mathrm{M}$ phosphate buffer $(\mathrm{pH} 3.5) /$ acetonitrile $(80: 20 \mathrm{v} / \mathrm{v})$ containing $0.5 \mathrm{mg}$ of $\mathrm{Na}_{2}$ EDTA. The flow rate was set at $0.6 \mathrm{ml} / \mathrm{min}$ for all separations.

In Vitro Human Skin Permeation Study In vitro skin permeation studies using 6-well plates were conducted according to Sandt et al. ${ }^{9)}$ Human skin was obtained from two female Caucasian donors, aged 35 and 46 years, directly after abdominal surgery. After isolation, the epidermal membranes were carefully transferred into 6-well plates on a Netwell insert (polyester $200 \mu \mathrm{m}$ mesh, $24 \mathrm{~mm}$ diameter, Costar) which allows contact of receiver solution with the basal membrane of epidermis, while the stratum corneum remains exposed to the air. The receiver solution consisted of saline $(0.9 \% \mathrm{NaCl}$ $\mathrm{w} / \mathrm{v}$ ) containing $0.01 \%$ sodium azide, and $0.3 \%$ bovine serum albumin. Wells were filled with $1.2 \mathrm{ml}$ receiver solution and 6-well plates were placed in a humidified incubator gassed with $5 \% \mathrm{CO}_{2}$ and $40 \% \mathrm{O}_{2}$ at $32{ }^{\circ} \mathrm{C}$. To obtain homogeneous distribution of the receiver solution the 6 -well plates were rocked on a platform $c a$. 9 times per minute. Test patches of $13 \mathrm{~mm}$ diameter were carefully applied to the epidermal membranes. Good contact between the patch and the epidermal membrane was ensured by placing a small metal object with a diameter of $12 \mathrm{~mm}$ and a weight of $5 \mathrm{~g}$ on top of the applied patch. At appropriate intervals, $0.6 \mathrm{ml}$ samples were taken from the receiver solution and replaced by the same volume of fresh receiver solution to maintain a constant volume.

Then $0.1 \mathrm{ml}$ of sample, with $50 \mu \mathrm{l}$ of an aqueous solution containing $0.5 \mathrm{ng}$ of internal standard (bromo-formoterol) and $1.0 \mathrm{ml}$ of $0.8 \mathrm{M}$ phosphate buffer $(\mathrm{pH} 9.5)$ were extracted with $3.0 \mathrm{ml}$ of tert-butylmethyl ether. After vigorous shaking for $15 \mathrm{~min}$, the organic layer was separated by centrifugation at $3000 \mathrm{rpm}$ for $10 \mathrm{~min}$, transferred to a centrifuge tube, evaporated in a nitrogen stream at $45^{\circ} \mathrm{C}$ and redissolved in $200 \mu \mathrm{l}$ of methanol $/ 50 \mathrm{mmol}$ ammonium carbonate $(1: 1$ $\mathrm{v} / \mathrm{v})$. The concentration of formoterol was determined using the LC/MS/MS method. This assay achieved a sensitivity limit of detection of $0.1 \mathrm{ng} / \mathrm{ml}$. All experiments were performed in accordance with the ethical standards issued by the ethical committee of Saitama Daiichi Pharmaceutical Co., Ltd.

Determination of FF Using LC/MS/MS The HPLC system was an 2690 Alliance (Waters) with a CAPCELL PAK C18 UG120 $(2.0 \times 150 \mathrm{~mm}$, Shiseido $)$ column. The mobile phase consisted of a mixture of methanol $/ 50 \mathrm{mmol} / \mathrm{l} \mathrm{am}$ monium hydrogen carbonate $(1: 1 \mathrm{v} / \mathrm{v})$ with a flow rate of $0.2 \mathrm{ml} / \mathrm{min}$. The column oven temperature was maintained at $40^{\circ} \mathrm{C}$ and the injection volume was $20 \mu \mathrm{l}$.

Mass spectrometric detection was performed on a TSQ7000 (Finnigan MAT) operating in the positive ion electrospray ionization mode. The mass was operated at $4.5 \mathrm{kV}$ spray voltage with an arbitrary value for the sheath gas flowrate (nitrogen) at a fixed 70 p.s.i. and an auxiliary gas flowrate fixed at 20 units. The heated capillary temperature was set at $250^{\circ} \mathrm{C}$.

Skin Irritation Tests Male rabbits (Japan white; 3.67$4.39 \mathrm{~kg}$ ), guinea pigs (Hartley strain; $340-392 \mathrm{~g}$ ), rats (Wistar strain; 160-206g) and miniature swine (Gettingen strain; $30 \mathrm{~kg}$ ) were used for primary skin irritation testing. One day before the experiment, back skin hair of rabbits and miniature swine and abdominal skin hair of guinea pigs and rats was clipped with an electric clipper, and thereafter shaved with an electric razor. Abraded areas were prepared by making four minor epidermal incisions with a hypodermic needle, two incisions perpendicular to the other two. The abrasions were sufficiently deep to penetrate the epidermis, but not to induce bleeding. Patches $(2.5 \mathrm{~cm} \times 2.5 \mathrm{~cm})$ were applied to the experimental groups and seemed with porous stretching bandages and then were removed after $24 \mathrm{~h}$ application. Approximately, $30 \mathrm{~min}, 24$ and $48 \mathrm{~h}$ thereafter, the sites were observed visually and evaluated according to the criteria of Draize ${ }^{10)}$ (Table 2).

\section{RESULTS AND DISCUSSION}

Effects of EC and OD on Skin Permeation of FF from EVA Matrix Patches In designing EVA matrix patches, it is essential to find an appropriate vehicle for effective penetration. ${ }^{5)}$ The in vitro skin permeability of FF across excised rat and human skin was investigated using EVA matrix patches containing $l$-menthol and NMP using a standard amount of FF per unit area.

Figures 1 and 2 show data for rat and human skin permeation of FF from matrix patches. Skin permeation of FF from EVA matrix patches with EC decreased remarkably compared with that without EC in rats after $24 \mathrm{~h}$. The thickness of the adhesive layer differed between patches with and with- 
Table 2. Evaluation Criteria for Skin Reactions

\begin{tabular}{ll}
\hline \hline \multicolumn{1}{c}{ Skin reactions } & Value \\
\hline Erythema and eschar formation & 0 \\
No erythema & 1 \\
Very slight erythema (barely perceptible) & 2 \\
Well defined erythema & 3 \\
Moderate to severe erythema & 4 \\
Severe erythema (beef redness) to slight eschar formation (injury in depth) & 0 \\
Edema formation & 1 \\
No edema & 2 \\
Very slight edema (barely perceptible) & 3 \\
Slight edema (edges of area well defined by definite elevation) & 4 \\
Moderate edema (raised approximately 1 mm) & \\
Severe edema (raised more than 1 mm and extending beyond the area of exposure) & \\
\hline
\end{tabular}

Primary irritation score

Mild: $0-2$. Moderate: $2-5$. Severe: $5-8$

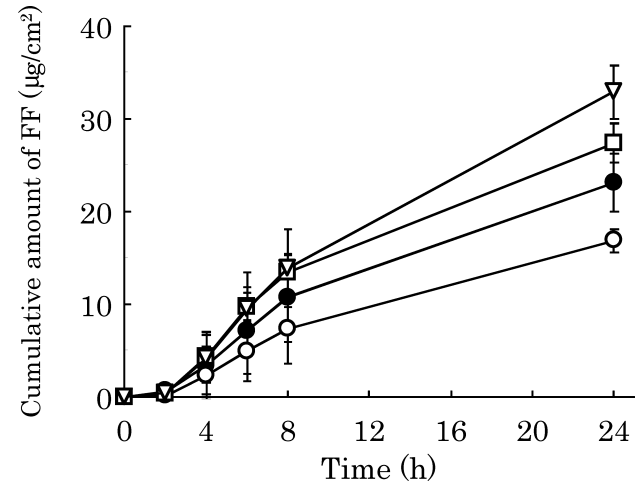

Fig. 1. Effects of EC and OD on Rat Skin Permeation of FF from EVA Matrix Patches Containing $l$-Menthol and NMP

-, without EC; $\bigcirc$, OD-0; $\square$, OD-0.5; $\nabla$, OD-1. Each point and bar represent the mean \pm S.D. of three determinations.

out EC. EVA matrix patches were transparent and the solubility of FF was not greatly affected by the coexistence of EC, so that FF may exist in a dissolved state. This may also suggest that the greater the thickness of the patch, the slower the release of the drug, and as a result, a lower skin permeation rate is observed.

Skin permeation of $\mathrm{FF}$ was remarkably enhanced by incorporation of OD instead of Ester Gum $\mathrm{H}$ in rats after $24 \mathrm{~h}$. The higher the concentration of OD in the EVA matrix patch, the greater the skin permeation of FF. Increase was about 1.94fold in rat and 6.33-fold in human skin after $24 \mathrm{~h}$ when the quantity of OD was raised from 0 to $1.0 \mathrm{mg}$ per square centimeter. Increasing thermodynamic activity of the drug and changing the barrier property of the skin may enhance the permeation. ${ }^{11)}$ A plasticizer plays an important role in increasing the mobility of the drug in the matrix patch and improving the tacky property of the matrix patch. ${ }^{12)}$ Therefore, OD presumably acts a plasticizer, imparting flexibility and improving fluidity.

One approach to improving the skin permeability of drugs is using penetration enhancers. ${ }^{13,14)}$ Effects of mixed solvents such as IPM/NMP ${ }^{15,16)}$ and $l$-menthol/ethano $1^{17)}$ have already been reported. EVA matrix patches contain $l$-menthol and NMP as enhancers, and skin permeation increases with increase in the $l$-menthol and NMP contents. ${ }^{5)}$ It seems that skin permeation of FF increased indirectly by the addition of

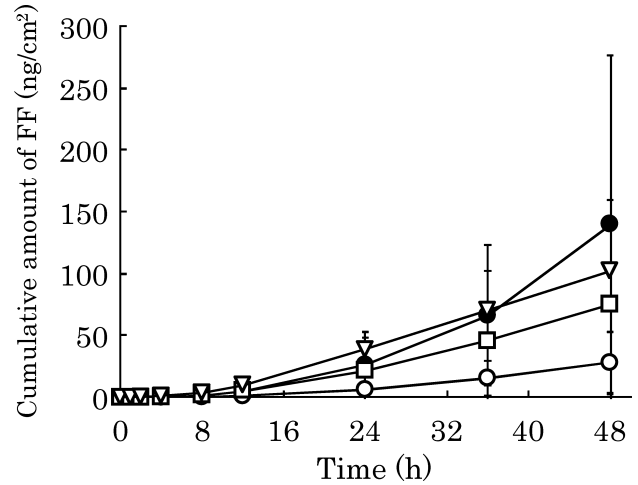

Fig. 2. Effects of EC and OD on Human Skin Permeation of FF from EVA Matrix Patches Containing $l$-Menthol and NMP

-, without EC; $\mathrm{O}$, OD-0; $\square$, OD-0.5; $\nabla$, OD-1. Each point and bar represent the mean \pm S.D. of four determinations.

OD owing to increase of thermodynamic activity of $l$-menthol as an enhancer.

Comparison of Skin Permeation of FF in Rats and Human Skin Effects on skin permeation of FF for all EVA matrix patches were similar in both rat and human skin, but the degree of rat skin permeation was 1000 times greater than with human skin after $24 \mathrm{~h}$. Permeation appeared to begin immediately, without any lag time, presumably because of the leaching activity of $l$-menthol and NMP in the matrix patches. Many studies have indicated mouse, rat or guinea pig skin to be more permeable than human skin. ${ }^{18-21)}$

Evaluation of Skin Irritation with EVA Matrix Patches The results of the primary skin irritation study are shown in Tables 3-6. With all EVA matrix patches, formation of very slight to well-defined erythema and very slight edema was observed in rabbits. The average scores for erythema and eschar formation and edema of without EC, OD-0, OD- 0.5 and OD-1 were $2.00,1.67,1.67$ and 1.83 after $24 \mathrm{~h}$ of matrix patch application, lesions then gradually disappearing. Based on the results, the primary irritation indices without EC, OD0 , OD- 0.5 and OD- 1 were $1.46,1.13,1.29$ and 1.38 , mildly but significantly different from the control value of 0.21 for the adhesive plaster group. In the guinea pig case, the primary irritation indices were $1.83,1.17,1.42$ and 1.42 , respectively, and there was no difference from the 1.50 of the control. In rats, the primary irritation indices were $1.00,0.50$, 
Table 3. Primary Rabbit Skin Irritation Scores for EVA Matrix Patches

\begin{tabular}{|c|c|c|c|c|c|c|}
\hline \multirow{2}{*}{$\begin{array}{c}\text { Test } \\
\text { substance }\end{array}$} & \multirow{2}{*}{$\begin{array}{c}\text { Skin } \\
\text { condition }\end{array}$} & \multirow{2}{*}{$\begin{array}{l}\text { Skin } \\
\text { reaction }\end{array}$} & \multicolumn{3}{|c|}{ Irritation score (Mean score) } & \multirow{2}{*}{ P. I. I. ${ }^{b)}$} \\
\hline & & & $24 \mathrm{~h}^{a)}$ & $48 \mathrm{~h}$ & $72 \mathrm{~h}$ & \\
\hline \multirow{5}{*}{ Without EC } & Abraded & $\mathrm{E}$ and $\mathrm{E}^{c)}$ & $9\left(1.50^{d)}\right)$ & $8(1.17)$ & $5(0.67)$ & \multirow{5}{*}{1.46} \\
\hline & & Edema & $4(0.67)$ & $1(0.17)$ & $0(0)$ & \\
\hline & Intact & $\mathrm{E}$ and $\mathrm{E}$ & $8(1.33)$ & $7(1.17)$ & $5(0.67)$ & \\
\hline & & Edema & $3(0.50)$ & $1(0.17)$ & $1(0.17)$ & \\
\hline & Total & & $24(2.00)$ & $17(1.42)$ & $11(0.92)$ & \\
\hline \multirow{5}{*}{ OD-0 } & Abraded & $\mathrm{E}$ and $\mathrm{E}$ & $7(1.17)$ & $7(1.33)$ & $3(0.50)$ & \multirow{5}{*}{1.13} \\
\hline & & Edema & $1(0.17)$ & $0(0.17)$ & $0(0)$ & \\
\hline & Intact & $\mathrm{E}$ and $\mathrm{E}$ & $8(1.33)$ & $7(1.17)$ & $4(0.67)$ & \\
\hline & & Edema & $4(0.67)$ & $0(0.17)$ & $0(0)$ & \\
\hline & Total & & $20(1.67)$ & $14(1.17)$ & $7(0.58)$ & \\
\hline \multirow{5}{*}{ OD- 0.5} & Abraded & $\mathrm{E}$ and $\mathrm{E}$ & $8(1.33)$ & $6(1.00)$ & $5(0.83)$ & \multirow{5}{*}{1.29} \\
\hline & & Edema & $3(0.50)$ & $1(0.17)$ & $0(0)$ & \\
\hline & Intact & $\mathrm{E}$ and $\mathrm{E}$ & $6(1.00)$ & $6(1.00)$ & $5(0.83)$ & \\
\hline & & Edema & $3(0.50)$ & $1(0.17)$ & $1(0.17)$ & \\
\hline & Total & & $20(1.67)$ & 14 (1.17) & $11(0.92)$ & \\
\hline \multirow{5}{*}{ OD-1 } & Abraded & $\mathrm{E}$ and $\mathrm{E}$ & $8(1.33)$ & $8(1.33)$ & $5(0.83)$ & \multirow{5}{*}{1.38} \\
\hline & & Edema & $4(0.67)$ & $1(0.17)$ & $0(0)$ & \\
\hline & Intact & $\mathrm{E}$ and $\mathrm{E}$ & $8(1.33)$ & $7(1.17)$ & $6(1.00)$ & \\
\hline & & Edema & $2(0.33)$ & $1(0.17)$ & $0(0)$ & \\
\hline & Total & & $22(1.83)$ & $17(1.42)$ & $11(0.92)$ & \\
\hline \multirow{5}{*}{$\begin{array}{l}\text { Adhesive } \\
\text { plaster }\end{array}$} & Abraded & $\mathrm{E}$ and $\mathrm{E}$ & $3(0.50)$ & $3(0.50)$ & $0(0)$ & \multirow{5}{*}{0.21} \\
\hline & & Edema & $0(0)$ & $0(0)$ & $0(0)$ & \\
\hline & Intact & $\mathrm{E}$ and $\mathrm{E}$ & $2(0.33)$ & $2(0.33)$ & $0(0)$ & \\
\hline & & Edema & $0(0)$ & $0(0)$ & $0(0)$ & \\
\hline & Total & & $5(0.42)$ & $5(0.42)$ & $0(0)$ & \\
\hline
\end{tabular}

Each test substance was used for 6 animals and was prepared for 6 abraded sites and 6 intact sites. a) Time after application. $\quad b)$ Primary irritation index $=\left[\sum\right.$ individual total skin irritation score (at $24 \mathrm{~h}+$ at $72 \mathrm{~h}) / 4] /$ number of animals. c) Erythema and eschar formation. d) Irritation score/the number of sites.

Table 4. Primary Guinea Pig Skin Irritation Scores for EVA Matrix Patches

\begin{tabular}{|c|c|c|c|c|c|}
\hline \multirow{2}{*}{$\begin{array}{c}\text { Test } \\
\text { substance }\end{array}$} & \multirow{2}{*}{$\begin{array}{c}\text { Skin } \\
\text { reaction }\end{array}$} & \multicolumn{3}{|c|}{ Irritation score (Mean score) } & \multirow{2}{*}{ P. I. I. ${ }^{b)}$} \\
\hline & & $24 \mathrm{~h}^{a)}$ & $48 \mathrm{~h}$ & $72 \mathrm{~h}$ & \\
\hline \multirow{3}{*}{ Without EC } & $\mathrm{E}$ and $\mathrm{E}^{c)}$ & $12\left(2.00^{d)}\right)$ & $7(1.17)$ & $5(0.83)$ & \multirow{3}{*}{1.83} \\
\hline & Edema & $4(0.67)$ & $4(0.67)$ & $1(0.17)$ & \\
\hline & Total & $16(2.67)$ & $11(1.83)$ & $6(1.00)$ & \\
\hline \multirow{3}{*}{ OD-0 } & $\mathrm{E}$ and $\mathrm{E}$ & $10(1.67)$ & $5(0.83)$ & $2(0.33)$ & \multirow{3}{*}{1.17} \\
\hline & Edema & $2(0.17)$ & $2(0.33)$ & $0(0)$ & \\
\hline & Total & $12(2.00)$ & $7(1.17)$ & $2(0.33)$ & \\
\hline \multirow{3}{*}{ OD- 0.5} & $\mathrm{E}$ and $\mathrm{E}$ & $12(2.00)$ & $7(1.17)$ & $4(0.67)$ & \multirow{3}{*}{1.42} \\
\hline & Edema & $1(0.17)$ & $1(0.17)$ & $0(0)$ & \\
\hline & Total & $13(2.17)$ & $8(1.33)$ & $4(0.67)$ & \\
\hline \multirow{3}{*}{ OD-1 } & $E$ and $E$ & $11(1.83)$ & $7(1.17)$ & $4(0.67)$ & \multirow{3}{*}{1.42} \\
\hline & Edema & $2(0.33)$ & $2(0.33)$ & $0(0)$ & \\
\hline & Total & $13(2.17)$ & $9(1.50)$ & $4(0.67)$ & \\
\hline \multirow{3}{*}{$\begin{array}{r}\text { Adhesive } \\
\text { plaster }\end{array}$} & $\mathrm{E}$ and $\mathrm{E}$ & $12(2.00)$ & $9(1.50)$ & $5(0.83)$ & \multirow{3}{*}{1.50} \\
\hline & Edema & $1(0.17)$ & $1(0.17)$ & $0(0)$ & \\
\hline & Total & $13(2.17)$ & 10 (1.67) & $5(0.83)$ & \\
\hline
\end{tabular}

Each test substance was used for 6 animals. a) Time after application. b) Primary irritation index $=\left[\sum\right.$ individual total skin irritation score $($ at $24 \mathrm{~h}+$ at $\left.72 \mathrm{~h}) / 2\right] /$ number of animals. c) Erythema and eschar formation. d) Irritation score/the number of sites.

0.50 and 0.63 , respectively, and there was again no difference from the 0.50 of controls. In the miniature swine case, no skin irritation was observed. Thus, slight irritation was observed in rabbits, but no significant irritation was seen in guinea pigs, rats and miniature swine in comparison with the control, adhesive plaster groups.

Skin irritation increased slightly without addition of EC as the vehicle with incorporation of OD instead of ester gum $\mathrm{H}$. 
Table 5. Primary Rat Skin Irritation Scores for EVA Matrix Patches

\begin{tabular}{|c|c|c|c|c|c|}
\hline \multirow{2}{*}{$\begin{array}{c}\text { Test } \\
\text { substance }\end{array}$} & \multirow{2}{*}{$\begin{array}{c}\text { Skin } \\
\text { reaction }\end{array}$} & \multicolumn{3}{|c|}{ Irritation score (Mean score) } & \multirow{2}{*}{ P. I. I. ${ }^{b}$} \\
\hline & & $24 \mathrm{~h}^{a)}$ & $48 \mathrm{~h}$ & $72 \mathrm{~h}$ & \\
\hline \multirow{3}{*}{ Without EC } & $\mathrm{E}$ and $\mathrm{E}^{c)}$ & $5\left(1.25^{d)}\right)$ & $4(1.00)$ & $3(0.75)$ & \multirow{3}{*}{1.00} \\
\hline & Edema & $0(0)$ & $0(0)$ & $0(0)$ & \\
\hline & Total & $5(1.25)$ & $4(1.00)$ & $3(0.75)$ & \\
\hline \multirow{3}{*}{ OD-0 } & $\mathrm{E}$ and $\mathrm{E}$ & $1(0.25)$ & $3(0.75)$ & $3(0.75)$ & \multirow{3}{*}{0.50} \\
\hline & Edema & $0(0)$ & $0(0)$ & $0(0)$ & \\
\hline & Total & $1(0.25)$ & $3(0.75)$ & $3(0.75)$ & \\
\hline \multirow{3}{*}{ OD- 0.5} & $\mathrm{E}$ and $\mathrm{E}$ & $2(0.50)$ & $3(0.75)$ & $2(0.50)$ & \multirow{3}{*}{0.50} \\
\hline & Edema & $0(0)$ & $0(0)$ & $0(0)$ & \\
\hline & Total & $2(0.50)$ & $3(0.75)$ & $2(0.50)$ & \\
\hline \multirow{3}{*}{ OD-1 } & $\mathrm{E}$ and $\mathrm{E}$ & $3(0.75)$ & $4(1.00)$ & $2(0.50)$ & \multirow{3}{*}{0.63} \\
\hline & Edema & $0(0)$ & $0(0)$ & $0(0)$ & \\
\hline & Total & $3(0.75)$ & $4(1.00)$ & $2(0.50)$ & \\
\hline \multirow{3}{*}{$\begin{array}{r}\text { Adhesive } \\
\text { plaster }\end{array}$} & $\mathrm{E}$ and $\mathrm{E}$ & $3(0.75)$ & $2(0.50)$ & $1(0.25)$ & \multirow{3}{*}{0.50} \\
\hline & Edema & $0(0)$ & $0(0)$ & $0(0)$ & \\
\hline & Total & $3(0.75)$ & $2(0.50)$ & $1(0.25)$ & \\
\hline
\end{tabular}

Each test substance was used for 4 animals. a) Time after application. b) Primary irritation index $=\left[\sum\right.$ individual total skin irritation score $($ at $24 \mathrm{~h}+$ at $\left.72 \mathrm{~h}) / 2\right] /$ number of animals. c) Erythema and eschar formation. d) Irritation score/the number of sites.

Table 6. Primary Miniature Swine Skin Irritation Scores for EVA Matrix Patches

\begin{tabular}{|c|c|c|c|c|c|}
\hline \multirow{2}{*}{$\begin{array}{c}\text { Test } \\
\text { substance }\end{array}$} & \multirow{2}{*}{$\begin{array}{c}\text { Skin } \\
\text { reaction }\end{array}$} & \multicolumn{3}{|c|}{ Irritation score (Mean score) } & \multirow{2}{*}{ P. I. I. ${ }^{b)}$} \\
\hline & & $24 \mathrm{~h}^{a)}$ & $48 \mathrm{~h}$ & $72 \mathrm{~h}$ & \\
\hline \multirow{3}{*}{ Without EC } & $\mathrm{E}$ and $\mathrm{E}^{c)}$ & $0\left(0^{d)}\right)$ & $0(0)$ & $0(0)$ & \multirow{3}{*}{0} \\
\hline & Edema & $0(0)$ & $0(0)$ & $0(0)$ & \\
\hline & Total & $0(0)$ & $0(0)$ & $0(0)$ & \\
\hline \multirow{3}{*}{ OD-0 } & $\mathrm{E}$ and $\mathrm{E}$ & $0(0)$ & $0(0)$ & $0(0)$ & \multirow{3}{*}{0} \\
\hline & Edema & $0(0)$ & $0(0)$ & $0(0)$ & \\
\hline & Total & $0(0)$ & $0(0)$ & $0(0)$ & \\
\hline \multirow{3}{*}{ OD- 0.5} & $\mathrm{E}$ and $\mathrm{E}$ & $0(0)$ & $0(0)$ & $0(0)$ & \multirow{3}{*}{0} \\
\hline & Edema & $0(0)$ & $0(0)$ & $0(0)$ & \\
\hline & Total & $0(0)$ & $0(0)$ & $0(0)$ & \\
\hline \multirow{3}{*}{ OD-1 } & $\mathrm{E}$ and $\mathrm{E}$ & $0(0)$ & $0(0)$ & $0(0)$ & \multirow{3}{*}{0} \\
\hline & Edema & $0(0)$ & $0(0)$ & $0(0)$ & \\
\hline & Total & $0(0)$ & $0(0)$ & $0(0)$ & \\
\hline \multirow{3}{*}{$\begin{array}{r}\text { Adhesive } \\
\text { plaster }\end{array}$} & $\mathrm{E}$ and $\mathrm{E}$ & $0(0)$ & $0(0)$ & $0(0)$ & \multirow{3}{*}{0} \\
\hline & Edema & $0(0)$ & $0(0)$ & $0(0)$ & \\
\hline & Total & $0(0)$ & $0(0)$ & $0(0)$ & \\
\hline
\end{tabular}

Each test substance was applied in 4 places. a) Time after application. b) Primary irritation index $=\left[\sum\right.$ individual total skin irritation score (at $24 \mathrm{~h}+$ at $\left.\left.72 \mathrm{~h}\right) / 2\right] /$ number of animals. c) Erythema and eschar formation. d) Irritation score/the number of sites.

Skin irritation with drugs and skin permeation enhancers is a common problem in transdermal delivery. ${ }^{22-25)}$ Moreover, adhesive plasters with low tensile stress and removal force and short stress relaxation time have lowest levels of skin irritation. $^{26)}$

Comparison of Skin Irritation in Different Species Skin irritation with EVA matrix patches was observed to be in the order of rabbits, guinea pigs, rats and miniature swine. Miniature swine skin resembles that of humans in anatomical and histochemical features, ${ }^{27)}$ and the size, orientation, and distribution of vessels ${ }^{28)}$ and has been reported to be somewhat less sensitive than human skin, in contrast to the rat and guinea pig cases. ${ }^{29)}$ Cosmetics and raw material skin sensitivity decrease in the following order: rabbit, guinea pig, rat, man and miniature swine. ${ }^{29)}$ An obvious difference was observed for skin irritation with EVA matrix patches.

Conclusions The combination of $\mathrm{EC}$ as a vehicle and OD as a plasticizer proved to be useful for enhancing skin permeation without increasing irritancy of EVA matrix patches containing FF. Clearly, skin permeation and irritation differ with the species of animal, but this is in degree rather than kind. It was concluded from our study that inclusion of EC and OD is feasible for improving EVA matrix patches for FF transdermal delivery. 


\section{REFERENCES AND NOTES}

1) Ida H., Arzneim.-Forsch., 26, 839-842 (1976).

2) Ida H., Arzneim.-Forsch., 26, 1337-1340 (1976).

3) Kono O., Morita M., Yakuri To Chiryo, 11, 4405-4416 (1983).

4) Nakajima S., Oishi M., Suetsugu S., Kono O., Mitsui K., Iwakura M., Kiso To Rinsho, 17, 3629-3637 (1983).

5) Kakubari I., Shinkai N., Kawakami J., Uruno A., Takayasu T., Yamauchi H., Takayama S., Takayama K., Biol. Pharm. Bull., 29, 513516 (2006)

6) Kakubari I., Nakamura N., Takayasu T., Yamauchi H., Takayama S., Takayama K., Biol. Pharm. Bull., 29, 146-149 (2006).

7) Borodkin S., Tucker F. E., J. Pharm. Sci., 63, 1359-1364 (1974).

8) Musolf M. C., "Transdermal Controlled Systemic Medications," ed. by Chien Y. W., Marcel Dekker Inc., New York, 1987, pp. 93-112.

9) van de Sandt J. J. M., Rutten A. A. J. J. L., van Ommen B., Toxicol. Appl. Pharmacol., 123, 144-150 (1993).

10) Draize J. H., "Dermal Toxicity," Appraisal of the Safety of Chemicals in Foods, Drugs and Cosmetics, The association of Food \& Drug Officials of the United States, Austin, Texas, 1959, pp. 46-59.

11) Møllgaard B., Hoelgaard A., Acta Pharm. Suec., 20, $433-442$ (1983).

12) Cho Y.-J., Choi H.-K., Int. J. Pharm., 169, 95-104 (1998).

13) Ogiso T., Iwaki M., Paku T., J. Pharm. Sci., 84, 482-488 (1995).

14) Manabe E., Tanaka S., Sugibayashi K., Morimoto Y., J. Pharm. Sci. Technol., Jpn., 58, 10-16 (1998).

15) Hoelgaard A., Møllgaard B., Baker E., Int. J. Pharm., 43, 233-240 (1988).
16) Seki T., Kawaguchi T., Juni K., Sugibayashi K., Morimoto Y., J. Controlled Release, 17, 41-47 (1991).

17) Morimoto Y., Sugibayashi K., Kobayashi D., Shoji H., Yamazaki J., Kimura M., Int. J. Pharm., 91, 9-14 (1993).

18) Hilton J., Woollen B. H., Scott R. C., Auton T. R., Trebilcock K. L., Wilks M. F., Pharm. Res., 11, 1396-1400 (1994).

19) Bartek M. J., Labudde J. A., Maibach H. I., J. Invest. Dermatol., 58, 114-123 (1972).

20) Sato K., Sugibayashi K., Morimoto Y., J. Pharm. Sic., 80, 104-107 (1991).

21) Ghosh T. K., Habib M. J., Childs K., Alexander M., Int. J. Pharm., 88, 391-396 (1992).

22) Kobayashi I., Hosaka K., Maruo H., Saeki Y., Kamiyama M., Konno C., Gemba M., J. Toxicol. Sci., 24, $103-112$ (1999).

23) Kobayashi I., Hosaka K., Ueno T., Maruo H., Kamiyama M., Konno C., Gemba M., Biol. Pharm. Bull., 19, 839-844 (1996).

24) Robinson M. K., Parsell K. W., Breneman D. L., Cruze C. A., Fundam. Appl. Toxicol., 17, 103-119 (1991).

25) Tenjarla S. N., Holbrook J. H., Puranajoti P., Pegg C., Lowe K. D., Jackson T. E., Smith A., J. Toxicol.-Cut. \& Ocular Toxicol., 14, 299 307 (1995).

26) Nakano Y., Saito K., Nitto Giho, 28, 50-57 (1990).

27) Montagna W., Yun J. S., J. Invest. Dermatol., 43, 11-21 (1964)

28) Forbes P. D., Adv. Biol. Skin, 9, 419-432 (1969).

29) Motoyoshi K., Toyoshima Y., Sato M., Yoshimura M., Cosmetics Toiletries, 94, 41-48 (1979). 